\title{
Raccoon (Procyon lotor) Activity is Better Predicted by Water Availability than Land Cover in a Moderately Fragmented Landscape
}

\author{
Author(s): Edward J. Heske and Adam A. Ahlers
}

Source: Northeastern Naturalist, 23(3):352-363.

Published By: Eagle Hill Institute

https://doi.org/10.1656/045.023.0302

URL: http://www.bioone.org/doi/full/10.1656/045.023.0302

BioOne (www.bioone.org) is a nonprofit, online aggregation of core research in the biological, ecological, and environmental sciences. BioOne provides a sustainable online platform for over 170 journals and books published by nonprofit societies, associations, museums, institutions, and presses.

Your use of this PDF, the BioOne Web site, and all posted and associated content indicates your acceptance of BioOne's Terms of Use, available at www.bioone.org/page/ terms of use.

Usage of BioOne content is strictly limited to personal, educational, and non-commercial use. Commercial inquiries or rights and permissions requests should be directed to the individual publisher as copyright holder. 


\title{
Raccoon (Procyon lotor) Activity is Better Predicted by Water Availability than Land Cover in a Moderately Fragmented Landscape
}

\author{
Edward J. Heske ${ }^{1, *}$ and Adam A. Ahlers ${ }^{2,3}$
}

\begin{abstract}
Procyon lotor (Raccoon) is a habitat and dietary generalist that reaches its greatest population densities in heterogeneous, moderately fragmented landscapes. Even within such landscapes, a variety of natural and anthropogenic habitat variables can influence the local activity of Raccoons, and therefore their potential impact as nest predators. We examined Raccoon activity at 34 baited track-stations over 3 summers in forested ravines in the Shawnee National Forest (SNF), IL. We found that the dependability of water at a survey site was the best predictor of Raccoon activity, overshadowing any potential influences of land cover in the surrounding landscape. Landscape-level effects on Raccoon population size and density are likely widespread throughout moderately fragmented regions like the SNF, but variation in local activity can be predicted by the distribution of critical resources (e.g., water, den sites).
\end{abstract}

\section{Introduction}

Habitat fragmentation negatively affects many species, but some thrive in fragmented or otherwise human-modified landscapes (Fahrig 2003). Procyon lotor L. (Raccoon), for example, exhibits greater abundance in heterogeneous than in homogeneous landscapes (Oehler and Litvaitis 1996, Pedlar et al. 1997). Greater abundance of Raccoons in fragmented landscapes is often assumed to cause negative effects for other species, such as greater rates of nest predation for songbirds (Donovan et al. 1997, Robinson et al. 1995, Schmidt 2003) and depredation of threatened species (e.g., turtles or their eggs; Feinberg and Burke 2003, Mitchell and Klemens 2000).

Although Raccoons are habitat and dietary generalists (Gehrt 2003), their abundance and activity might be influenced by variations in resource distribution at both the landscape and local scales (Beasley and Rhodes 2010, Dijak and Thompson 2000). Raccoons are primarily associated with forest cover (e.g., Beasley et al. 2007a, Chamberlain et al. 2007, Gehring and Swihart 2003), but they attain their greatest densities in moderately forested landscapes rather than continuously forested ones (Oehler and Litvaitis 1996) and prefer to reside in areas characterized by heterogeneity in land cover (Byrne and Chamberlain 2011). Raccoons often use forest edges, particularly in moderately fragmented landscapes

\footnotetext{
${ }^{1}$ Illinois Natural History Survey, Prairie Research Institute, University of Illinois, Champaign, IL 61820. ${ }^{2}$ Department of Natural Resources and Environmental Sciences, University of Illinois, Urbana, IL 61801. ${ }^{3}$ Current address - Horticulture, Forestry and Recreation Resources, Kansas State University, Manhattan, KS 66506. Corresponding author - eheske@ illinois.edu.
}

Manuscript Editor: Michael Cramer 
(e.g., Barding and Nelson 2008, Houle et al. 2004, Renfrew and Ribic 2003), but whether they exhibit an edge effect likely depends on the type of edge, and local and seasonal resource availability (e.g., Dijak and Thompson 2000, Heske et al. 1999, Newton and Heske 2001).

Raccoons often exploit human-dominated habitats (Rodewald and Gehrt 2014). They can reach high densities in urban or developed habitats (Haskell et al. 2013, Prange and Gehrt 2004) and are positively associated with anthropogenic food sources (Bozek et al. 2007, Prange et al. 2004). Raccoons also often utilize agricultural areas, such as Zea mays L. (Corn) fields when crops are available (Beasley and Rhodes 2008, Beasley et al. 2007b). Results vary, but some studies show a positive association between Raccoon activity and row-crop agriculture, primarily at forest-cornfield edges (Beasley and Rhodes 2010, Pedlar et al. 1997).

Activity at a particular site may be influenced by local resources, such as the availability of den sites, even within landscapes characterized by high Raccoon abundance (Beasley and Rhodes 2012). Henner et al. (2004) noted that availability of water influenced den-site selection on prairie landscapes in Mississippi. Others have suggested that water availability could influence home-range aggregation (Gehrt and Fritzell 1998) or size (Beasley and Rhodes 2010). Thus, Raccoon abundance and space use can be influenced by a variety of landscape and local factors. Conservation biologists and managers of protected natural areas need to understand how these factors affect Raccoon activity at a specific location, and the potential impact of Raccoon activity on songbird nests or other potential prey at that site.

We used baited track-stations to quantify Raccoon activity in a moderately fragmented landscape (Robinson et al. 1995) where Raccoons occurred at high abundance (Cottam et al. 2009) and ecological processes, such as edge effects, were predicted to be evident (Donovan et al. 1997). We compared the predictive power of models based on 5 hypotheses drawn from the literature. We assumed that when a hypothesis predicted higher abundance, we would observe its effect as greater activity at a track station. However, greater activity at a track station also could result from greater use of a site by individual Raccoons. In either case, the ecological impact of Raccoons (e.g., as nest predators) at a site is likely to be a consequence of local activity. Our 5 predictions were: (1) Raccoon activity at a site is positively related to habitat heterogeneity in the surrounding landscape, (2) Raccoon activity is positively related to the amount of forest edge in the surrounding landscape, (3) Raccoon activity is positively related to the amount of anthropogenic resources in the surrounding landscape, (4) Raccoon activity is positively related to the amount of agricultural land in the surrounding landscape, and (5) Raccoon activity is positively related to the presence of critical resources (i.e., water or proximity of an anthropogenic food source) at the site.

\section{Methods}

\section{Study area}

We conducted our study in the Shawnee National Forest (SNF) in southern Illinois $\left(37^{\circ} 43^{\prime} \mathrm{N}, 88^{\circ} 31^{\prime} \mathrm{W}\right)$. The SNF consists of a 112,302 -ha mixture of protected 
and private areas characterized by a patchwork of Quercus-Carya (oak-hickory) forest on slopes and uplands, interspersed with agricultural fields, grasslands, and riparian floodplain forests. The topography ranges from gently rolling floodplains dominated by grassland and agriculture, to steep, forested hillsides with narrow ridgetops and ravines. Total elevational relief is $\sim 225 \mathrm{~m}$. The western SNF includes the easternmost extension of the Ozark Mountains and the eastern SNF lies in the Shawnee Hills region. Mean temperatures in the region range from $20.4{ }^{\circ} \mathrm{C}$ in the summer to $7.9^{\circ} \mathrm{C}$ in the winter, with a mean annual precipitation of $112 \mathrm{~cm}$.

\section{Assessing Raccoon activity}

We selected 34 survey sites distributed around the SNF (Fig. 1) based on features we identified on US Geological Survey 7.5-min topographical maps and data from a simultaneous study examining mesopredator activity and songbird-nest success in forest interiors in the SNF (Cottam et al. 2009). We focused on forested areas owned by the US Forest Service (USFS), stratified to include the entire range of the $\mathrm{SNF}$, and including a mix of forest-fragment sizes and landscape settings (e.g., forest, grassland, and agricultural land in the surrounding area). All survey sites were in ravine beds, $25-50 \mathrm{~m}$ from a roadside (all gravel or single-lane rural roads), and under closed forest-canopy. We placed 2-3 survey sites in the same vicinity but in separate ravines to obtain multiple samples from different parts of the SNF, while decreasing the probability of the same Raccoons visiting both sites. We attempted to place survey sites $>0.5 \mathrm{~km}$ apart, but 2 pairs of sites were $\sim 0.35 \mathrm{~km}$ apart due to constraints in topography (i.e., locations of nearby ravines). In 3 sampling areas, 2 sites were located in the same ravine due to limited habitat availability, but these were all spaced $>1.0 \mathrm{~km}$ apart and located on opposite sides of the road to increase

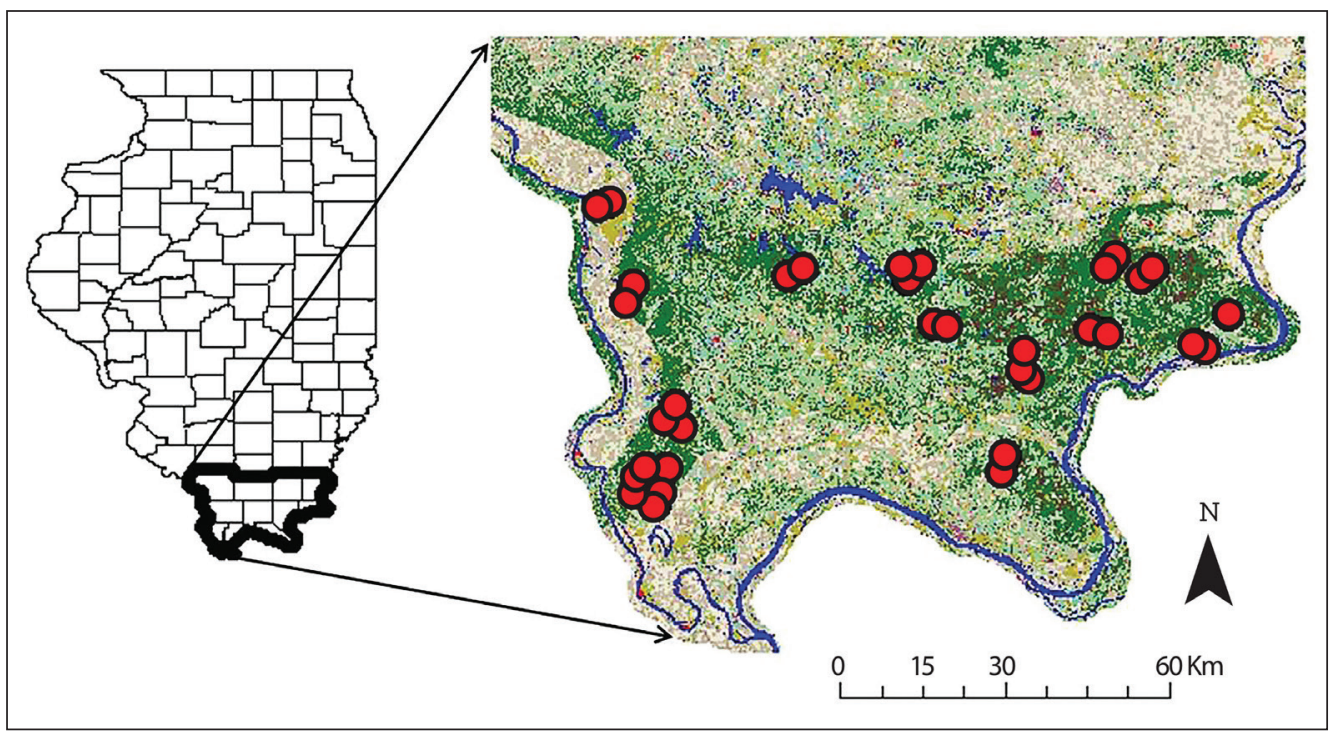

Figure 1. Map of the study area in southern Illinois, showing locations of survey sites (red circles). Dark green indicates forest, light green indicates grassland, tan indicates row-crop agriculture. 
independence. Mean nearest-neighbor distance between survey sites was $1.33 \mathrm{~km}$ $(\mathrm{SD}=1.27 \mathrm{~km}$, range $=0.35-7.51 \mathrm{~km})$.

We used track stations as an index of Raccoon activity at each site (Cottam et al. 2009, Dijak and Thompson 2000, Heske 1995, Oehler and Litvaitis 1996, Pedlar et al. 1997). Each track station consisted of a 1-m-diameter circle of fine sand mixed with mineral oil to help retain tracks set in a flat area cleared of vegetation and baited in the center with a 2-cm-diameter plaster disk saturated with fatty acid scent (Pocatello Supply Depot, Pocatello, ID). We set up track stations during the day when no rain was predicted, and checked them the following day. Because of the time required to access survey sites, we sampled track stations on one side of the SNF and immediately afterward set up and ran track stations on the other side of the SNF. We conducted 1-night surveys at each site in May, June, and July 2001, and increased sampling to 5 bi-weekly surveys in May, June, and July 2002 and 2003, for a total of 13 surveys per site. We replenished sand and bait for each survey.

We pooled track-station data from all 3 years to assess Raccoon activity at each site. During each survey, we recorded track data as presence or absence of Raccoons because we could not distinguish tracks left by multiple individuals at a site. We calculated our index of activity for each site as the sum of all visits to track stations by Raccoons over 13 surveys. We assumed that sites visited more often by Raccoons had higher levels of Raccoon activity than sites visited less often.

\section{Habitat metrics and model development}

We imported digital land-cover maps into a GIS (ArcMap 10.0; ESRI 20 10) and extracted all relevant landscape-level information from within a 1-km-radius buffer surrounding each track station. We chose this scale of observation because previous studies have detected landscape-level effects using buffers of this size (e.g., Beasley and Rhodes 2010, Gehring and Swihart 2003, Pedlar et al. 1997). Additionally, the overall area within buffers $\left(3.14 \mathrm{~km}^{2}\right)$ was considerably larger than the typical home-range size reported for Raccoons (Beasley and Rhodes 2007, Gehrt 2003). Although buffered areas around neighboring survey stations overlapped to varying extents at this scale, the proportion of buffered area that overlapped with a neighbor was always $<50 \%$, and quantitative metrics differed between neighboring sites. In spite of the large area comprising the SNF, we were constrained by the number of ravines within federally owned forest that were accessible by road, and accepted this overlap between some sites to increase sample size and allow multiple sites within different parts of the SNF. We measured areas of forest (all types combined), row-crop agriculture, grassland, wetland, lakes and ponds, developed (pooled low, medium, and high urban categories) land-cover, and linear length of forest edge within each buffered area. We calculated the Euclidean distance from each track station to the nearest human dwelling or campground.

We intended to place all sites adjacent to streams in ravines to control for topographic influences on Raccoon movements and the species' known affinity for water, but when setting up sites we found that topographic maps and land-cover maps did not accurately predict the presence of water in streambeds in ravines. We therefore 
generated an index of the dependability of water at each track station. Water-index values ranged from 1 to 3 , where 1 indicated dry ravine beds with water present only immediately following rain; 2 indicated flowing water present intermittently with a few small, shallow pools remaining except after extended dry periods; and 3 indicated flowing water, sometimes including pools, consistently present. This variable allowed us to model the influence of the dependability of finding water at a site on Raccoon activity, rather than just the presence of a streambed that might have water at some times but not others.

To evaluate our predictions, we generated the following parameters to be used as covariates in our models:

(1) Habitat heterogeneity (Heterogeneity). We used FRAGSTATS v4 (McGarigal et al. 2012) to measure Shannon's evenness index based on the areas of forest, agricultural, grassland, wetland, lakes and ponds, and developed cover within each buffered area, and related evenness to Raccoon activity at that track station. We chose to use evenness rather than a diversity index to quantify habitat heterogeneity because the number of habitat types considered (6) was constant among sites.

(2) Forest edge (Edge). We related Raccoon activity to the linear length of forest edge within each 1-km buffer, which was predominantly forest-cropfield edge or forest-grassland edge. We included both types of forest edge because either might provide access to food resources and be used as a travel lane by mesopredators (Marini et al. 1995).

(3) Anthropogenic resources (Human influence). We considered only the potential for non-agricultural human influences-homes, farmsteads, and campgrounds or picnic areas - to affect Raccoon activity. We related Raccoon activity to the proportion of the area within the $1-\mathrm{km}$ buffers around each track station consisting of any residential or other developed property. (4) Agricultural-land cover (Ag). We related Raccoon activity to the proportion of the area within the $1-\mathrm{km}$ buffers around each track station covered by row-crop agriculture. We did not determine whether fields were planted in Corn or Glycine $\max (\mathrm{L}$.$) Merr. (Soybean) at the times of our surveys, but it$ was probably a mixture because farming practice in this region was to alternate crops between years.

(5) Critical resources. We evaluated 2 types of resources with separate models. First, we related Raccoon activity to the dependability of water at the site, as categorized by our water index (Water index). Second, we related Raccoon activity at a track station to its linear distance to the nearest human dwelling or campground (Dist. human). The latter differed from our Human Influence parameter by considering how close the track station was to the nearest point of potential human-generated food resources rather than an overall area of human influence within the buffer.

We used linear models (PROC MIXED; SAS Institute, Inc., Carey, NC ) to model our response variable (index of Raccoon activity) as a function of our 
selected covariates. Landscape covariates showed a range of variation among our survey sites (Fig. 2). Water index was modeled as a categorical variable. Thirteen sites received a water index value of 1,10 sites received a 2, and 11 sites received a 3 . The distance from a track station to a human dwelling ranged from 130-1740 m (mean $=628, \mathrm{SD}=374)$. Our candidate model set included a model for each of our covariates considered singly $(n=6)$, additive effects of pairs of covariates, and an intercept-only model. Covariates exhibiting strong multicollinearity $(r \geq 0.50)$ were not included in the same model. To avoid over-parameterization of our data while still maximizing model likelihood, we constrained each model to the intercept and error terms plus up to 2 additional covariates. We examined residual plots to ensure assumptions of normality were met for all models and evaluated competing models using an information-theoretic approach (Burnham and Anderson 2002, Arnold 2010); and models with $\Delta \mathrm{AIC}_{\mathrm{c}}$ values of $\leq 2$ were considered competitive.

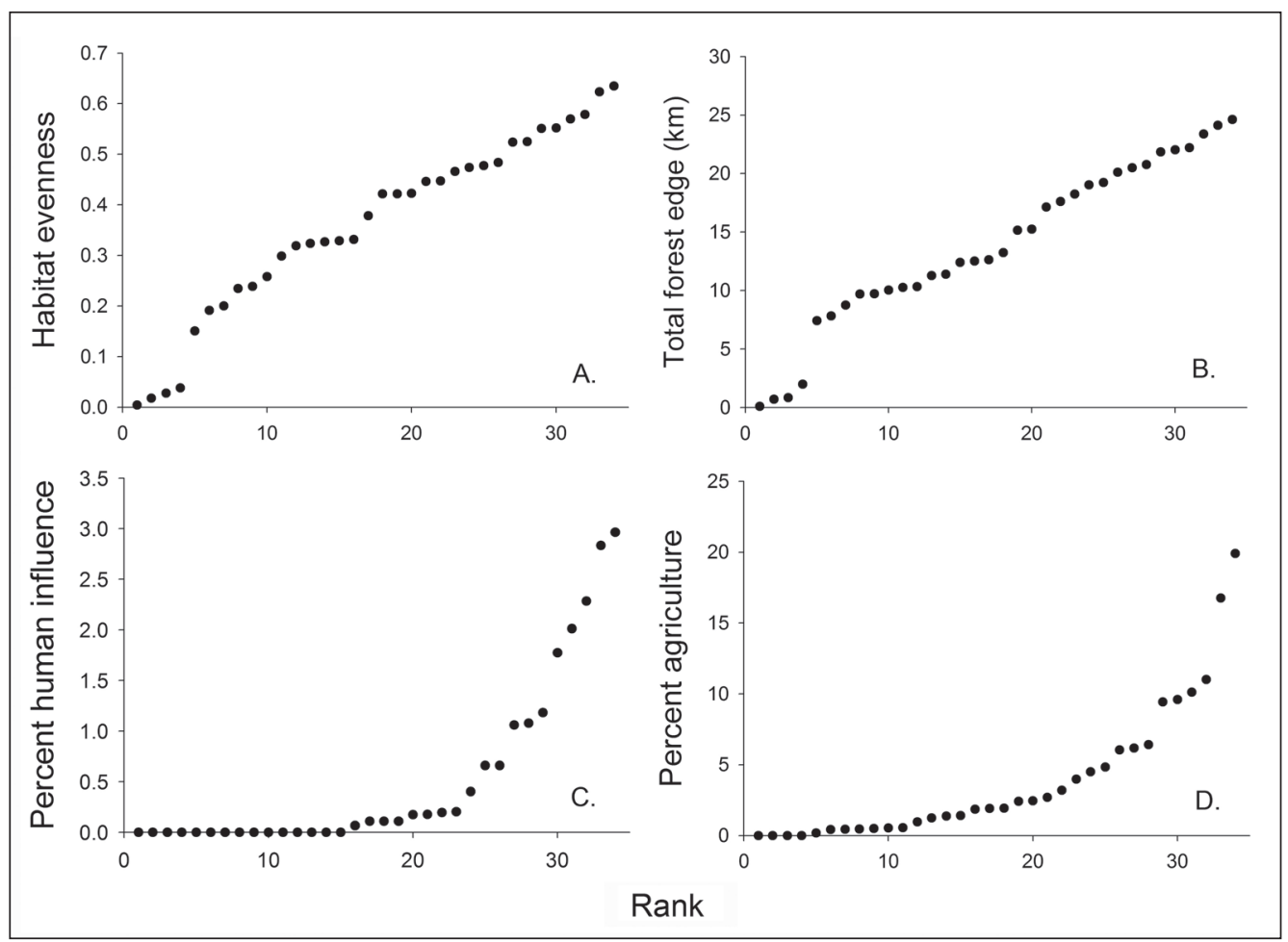

Figure 2. Cumulative ranking of track stations $(n=34)$ that were placed in ravines in closedcanopy hardwood forest, 25-50 m from a road; locations varied in surrounding land-cover and landscape variables hypothesized to influence Procyon lotor (Raccoon) activity. (A) Habitat evenness $=$ Shannon's evenness index of land-cover types within a 1-km radius; (B) Total forest edge $=$ total linear forest-edge with a $1-\mathrm{km}$ radius of the track station; (C) Percent human influence $=$ percentage of landscape within a $1-\mathrm{km}$ radius in farmsteads, private homes, or campgrounds; and (D) Percent agriculture = percentage of land cover within a $1-\mathrm{km}$ radius in agricultural production. 


\section{Results}

We detected Raccoons at least once during the 3 y of our surveys at 32 of 34 $(94 \%)$ of our track stations. The proportion of track stations where we documented Raccoons varied slightly among years $(2001=79 \% ; 2002=79 \% ; 2003=68 \%)$. Raccoon activity at each site ranged from 0-9 (median $=4)$. Overall, we recorded 132 site visits by Raccoons, 54 by Didelphis virginiana (Kerr) (Virginia Opossum); 14 by Canis latrans Say (Coyote); 9 by either Vulpes vulpes L. (Red Fox) or Urocyon cinereoargeteus (Schreber) (Gray Fox), which we pooled because of difficulty distinguishing species; 4 by Felis catus L. (Domestic Cat), 3 by Canis familiaris L. (Domestic Dog); 3 by Mustela frenata Lichtenstein (Long-tailed Weasel), and 2 by Lynx rufus (Schreber) (Bobcat).

Our best approximating model indicated that dependability of water was the only factor influencing Raccoon activity at our sites (Table 1 ). The $2^{\text {nd }}$ - and $3^{\text {rd }}$ ranked models included Water index and either Edge or Dist. human, but neither additional variable improved the fit of the model substantially, as indicated by little change in the log-likelihood value. Thus, these variables did not improve predictability of Raccoon activity above that based on dependability of water (Arnold 2010). Analysis of variance (ANOVA) indicated Raccoon activity differed among the water-index categories $\left(F_{2,31}=9.47, P<0.001\right.$; Fig. 3$)$. Tukey-Kramer tests indicated that Raccoon activity at sites with Water index 1 was lower than at sites with Water Index of 2 or $3(P<0.005)$, but activity at sites with Water index 2 or 3 did not differ $(P=0.98)$.

\section{Discussion}

Raccoon activity at track stations in a moderately fragmented, heterogeneous landscape was best predicted by dependability of finding water at the site. Raccoon use of habitats associated with water is well known (Gehrt 2003), but our results show that sites with semi-permanent or predictable water resources have higher

Table 1. Ranking of models used to predict relative Raccoon (Procyon lotor) activity at 34 track stations within a moderately fragmented forest landscape in southern Illinois, 2001-2003. Only the $\sum \omega_{i}=0.99$ model set, plus the intercept-only model, is shown. $\mathrm{K}$ is the number of parameters in the model including the intercept and error terms, $\omega_{i}$ is the estimated model weight, and Log likelihood is the calculated model goodness-of-fit. Explanatory variables include: Water index (index of the availability of surface water adjacent to track station), Edge (total linear forest-edge within a 1-km radius), Dist. human (Euclidian distance from track station to nearest human dwelling or campground), Human influence (proportion of landscape within a $1-\mathrm{km}$ radius occupied by farmsteads, private homes, or campgrounds), and Ag (proportion of landscape within a 1-km radius in agricultural production).

\begin{tabular}{lcccc} 
Model & $\mathrm{K}$ & $\Delta \mathrm{AICc}$ & $\omega_{i}$ & Log likelihood \\
\hline Water index & 4 & 0.00 & 0.640 & -71.38 \\
Water index + Edge & 5 & 2.60 & 0.170 & -71.29 \\
Water index + Dist. human & 5 & 2.69 & 0.170 & -71.34 \\
Human influence & 3 & 7.78 & 0.010 & -76.56 \\
Ag + Human influence & 4 & 9.68 & 0.005 & -76.21 \\
Intercept only & 2 & 11.22 & 0.002 & -79.48 \\
\hline
\end{tabular}


levels of Raccoon activity than sites with irregular occurrence of water. Landscape variables shown to affect Raccoon abundance or habitat use in other studies showed little influence on activity at our sites. This finding does not mean that those landscape variables have no effect on Raccoons, particularly through population effects at the regional scale, but that they were overshadowed by the dependability of water at our site-specific scale. Prior studies of Raccoons in the SNF also did not detect an effect of forest-agricultural edges (Heske 1995) or the amount of agriculture or grassland in the matrix (i.e., $3-\mathrm{km}$ buffer) surrounding large forest-tracts (Cottam et al. 2009) on Raccoon activity at track stations. Our track stations were all located on SNF land that was forested; thus, the areas of land-cover by agriculture and human development within our 1-km buffers were small, and no track stations were in close proximity $(<100 \mathrm{~m})$ to a potentially attractive anthropogenic food source. Although our site selection diminished our ability to evaluate effects of anthropogenic variables per se, one of our goals was to assess factors affecting variation in activity of Raccoons, important predators of songbird nests (Heske et al. 2001) in the SNF, and the ranges of covariates included in our study were typical of those to which forest-nesting songbirds would be exposed.

Activity at a track station could reflect differences in Raccoon abundance among sites or habitat use by resident Raccoons. Raccoons were widespread and abundant throughout our study area; only 2 of our track stations did not result in a Raccoon detection during our surveys. We suggest that any effects of landscape heterogeneity, forest edge, and land-cover types on populations of Raccoons are similarly

Figure 3. Relationship between Procyon lotor (Raccoon) activity (number of surveys at which Raccoon tracks were present at a site, 13 max.) and availability of water at 34 track stations within a moderately fragmented forest landscape in southern Illinois, 20012003. Water index values: $1=$


water only present immediately after rain; 2 = running water present intermittently, shallow pools of standing water present during most surveys; and 3 = running water, sometimes including pools, consistently present. 
widespread and diffuse (see also Cottam et al. 2009). Many previous studies have examined habitat use by Raccoons (e.g., Beasley et al. 2007a; Chamberlain et al. 2003, 2007), but few studies have related population-level responses to landscape variation at larger spatial scales (e.g., Donovan et al. 1997, Oehler and Litvaitis 1996). Population-level studies require making estimates of complex parameters, such as population density and vital rates, as well as quantifying landscape metrics at spatial scales relevant to populations. It is useful to begin by examining habitat use of individuals, but extrapolating results to the landscape level may not be appropriate. However, information on factors affecting population density across landscapes is likely to be as important to conservation biologists as information on factors determining site use by resident Raccoons, and more studies of the former are needed. Beasley and Rhodes (2012) have taken a step in this direction by determining that variability in offspring production by Raccoons was linked to availability of denning resources in a highly fragmented, agricultural landscape.

The buffered areas around our track stations had low percent cover of human dwellings and agricultural land, with only a few exceptions (Fig. 2), and these areas apparently did not exert a strong influence on Raccoon activity at our sites. Bozek et al. (2007) reported that habitats associated with anthropogenic food sources were selected by Raccoons most often within urban areas, at an intermediate level in suburban areas, and were not selected in rural areas. Increased Raccoon activity near crop fields has been reported (Chamberlain et al. 2007, Houle et al. 2011), but proximity to crop fields did not affect our index of Raccoon activity in forested ravines.

In contrast to the lack of relationships with other landscape variables, Raccoon activity showed a clear relationship with the dependability of water at sites in our study. Other studies also have concluded that water is an important resource affecting Raccoon distribution (Chamberlain et al. 2007, Dijak and Thompson 2000, Gehrt and Fritzell 1998, Henner et al. 2004). Beasley and Rhodes (2010) suggested that Raccoons have smaller home ranges in larger compared to smaller forest-patches because water is limited in many of the latter sites, but they did not examine the influence of water directly (see also Beasley et al. 2007a). Our study suggests that even if landscape-level parameters that affect population density or home-range placement have been considered, sites with semi-permanent and predictable water resources are likely to attract greater Raccoon activity than sites with inconsistent presence of water, even when those sites are located in potential travel lanes, such as forested ravines. Water might not be a resource managers want to limit, but variation in its dependability could generate differences in nest-predation rates among ravines. Cottam et al. (2009) also suggested that local-scale processes might better explain variation in songbird-nest success than landscape processes (e.g., matrix effects) in fragmented regions. We show here that Raccoons tend to be more active within ravines where the presence of water is dependable rather than merely occasional.

We suggest that the best way to further advance our understanding of how anthropogenic landscape-change affects Raccoons and other mesopredators, and 
therefore, the cascading ecological consequences of changes in their density and local activity, is to focus on variation at the population level. One approach is to examine how vital rates, such as reproduction and survival, which can affect density, vary across landscapes (e.g., Beasley and Rhodes 2012). The many studies on habitat use in recent decades have provided good insights into the local space-use of Raccoons. The next logical step is to conduct studies to evaluate how well these insights scale upward.

\section{Acknowledgments}

We thank S. Robinson for help in selecting the field sites, T. Lyons for assistance with statistical analyses, and the National Science Foundation (DEB99-04058) and the Illinois Natural History Survey for financial support.

\section{Literature Cited}

Arnold, T.W. 2010. Uninformative parameters and model selection using Akaike's information criterion. Journal of Wildlife Management 74:1175-1178.

Barding, E.E., and T.A. Nelson. 2008. Raccoons use habitat edges in northern Illinois. American Midland Naturalist 159:394-402.

Beasley, J.C., and O.E. Rhodes Jr. 2008. Relationship between Raccoon abundance and crop damage. Human-Wildlife Conflicts 2:248-259.

Beasley, J.C., and O.E. Rhodes Jr. 2010. Influence of patch- and landscape-level attributes on the movement behavior of Raccoons in agriculturally fragmented landscapes. Canadian Journal of Zoology 88:161-169.

Beasley, J.C., and O.E. Rhodes Jr. 2012. Are Raccoons limited by the availability of breeding resources? Evidence of variability in fecundity at fine spatial-scales. Journal of Wildlife Management 76:1718-1724.

Beasley, J.C., T.L. DeVault, M.I. Retamosa, and O.E. Rhodes Jr. 2007a. A hierarchical analysis of habitat selection by Raccoons in northern Indiana. Journal of Wildlife Management 71:1125-1133.

Beasley, J.C., T.L. DeVault, and O.E. Rhodes Jr. 2007b. Home-range attributes of Raccoons in a fragmented agricultural region of northern Indiana. Journal of Wildlife Management 71:844-850.

Bozek, C.K., S. Prange, and S.D. Gehrt. 2007. The influence of anthropogenic resources on multi-scale habitat selection by Raccoons. Urban Ecosystems 10:413-425.

Burnham, K.P., and D.R. Anderson. 2002. Model Selection and Multimodel Inference: A Practical Information-theoretic Approach. $2^{\text {nd }}$ Edition. Springer-Verlag, New York, NY. $488 \mathrm{pp}$.

Byrne, M.E., and M.J. Chamberlain. 2011. Seasonal space use and habitat selection of adult Raccoons (Procyon lotor) in a Louisiana bottomland hardwood-forest. American Midland Naturalist 166:426-434.

Chamberlain, M.J., L.M. Conner, B.D. Leopold, and K.M. Hodges. 2003. Space use and multi-scale habitat selection of adult Raccoons in central Mississippi. Journal of Wildlife Management 67:334-340.

Chamberlain, M.J., J. Austin, B.D. Leopold, and L.W. Burger Jr. 2007. Effects of landscape composition and structure on core-use areas of Raccoons (Procyon lotor) in a prairie landscape. American Midland Naturalist 158:113-122. 
Cottam, M.R., S.K. Robinson, E.J. Heske, J.D. Brawn, and K.C. Rowe. 2009. Use of landscape metrics to predict avian-nest survival in a fragmented Midwestern forest landscape. Biological Conservation 142:2464-2475.

Dijak, W.D., and F.R. Thompson III. 2000. Landscape and edge effects on the distribution of mammalian predators in Missouri. Journal of Wildlife Management 64:209-216.

Donovan, T.M., P.W. Jones, E.M. Annand, and F.R. Thompson III. 1997. Variation in localscale edge effects: Mechanisms and landscape context. Ecology 78:2064-2075.

Environmental Systems Research, Inc. (ESRI). 2010. ArcMap. Version 10.0. Redlands, CA.

Fahrig, L. 2003. Effects of habitat fragmentation on biodiversity. Annual Review of Ecology and Systematics 34:487-515.

Feinberg, J.A., and R.L. Burke. 2003. Nesting ecology and predation of Diamondback Terrapins, Malaclemys terrapin, at Gateway National Recreation Area, New York. Journal of Herpetology 37:517-526.

Gehring, T.M., and R.K. Swihart. 2003. Body size, niche breadth, and ecologically scaled responses to habitat fragmentation: Mammalian predators in an agricultural landscape. Biological Conservation 109:283-295.

Gehrt, S.D. 2003. Raccoon and allies. Pp. 611-634, In G.A. Feldhamer, B.C. Thompson, and J. A. Chapman (Eds.). Wild Mammals of North America. $2^{\text {nd }}$ Edition. Johns Hopkins University Press, Baltimore, MD. 1216 pp.

Gehrt, S.D., and E.K. Fritzell. 1998. Resource distribution, female home-range dispersion, and male social interactions: Group structure in a solitary carnivore. Animal Behaviour 55:1211-1227.

Haskell, D.E., C.R. Webster, and D.J. Flaspohler. 2013. Relationship between carnivore distribution and landscape features in the northern highlands ecological landscape of Wisconsin. American Midland Naturalist 169:1-16.

Henner, C.M., M.J. Chamberlain, B.D. Leopold, and L.W. Burger Jr. 2004. A multi-resolution assessment of Raccoon den selection. Journal of Wildlife Management 68:179-187.

Heske, E.J. 1995. Mammal abundances on forest-farm edges versus forest interiors in southern Illinois: Is there an edge effect? Journal of Mammalogy 76:800-808.

Heske, E.J., S.K. Robinson, and J.D. Brawn. 1999. Predator activity and predation on songbird nests on forest-field edges in east-central Illinois. Landscape Ecology 14:345-354.

Heske, E.J., S.K. Robinson, and J.D. Brawn. 2001. Nest predation and neotropical migrant songbirds: Piecing together the fragments. Wildlife Society Bulletin 29:52-61.

Houle, M., D. Fortin, J. Mainguy, and P. Canac-Marquis. 2004. Landscape composition and structure influence the abundance of mesopredators: Implications for the control of the Raccoon (Procyon lotor) variant of rabies. Canadian Journal of Zoology 89:1107-1116.

Marini, M.A., S.K. Robinson, and E.J. Heske. 1995. Edge effects on nest predation in the Shawnee National Forest, Southern Illinois. Biological Conservation 74:203-213.

McGarigal K., S.A. Cushman, and E. Ene. 2012. FRAGSTATS v4: Spatial-pattern analysis program for categorical and continuous maps. Computer software program produced at The University of Massachusetts, Amherst, MA. Available at http://www.umass.edu/ landeco/research/fragstats/fragstats.html. Accessed 5 November 2012.

Mitchell, J.C., and M.W. Klemens. 2000. Primary and secondary effects of habitat alteration. Pp. Pp. 5-32, In M.W. Klemens (Ed.). Turtle Conservation. Smithsonian Institution Press, Washington, DC. 334 pp.

Newton, J.L., and E.J. Heske. 2001. Predation on artificial nests in small grassland-patches in east-central Illinois. American Midland Naturalist 145:29-38. 
Oehler, J.D., and J.A. Litvaitis. 1996. The role of spatial scale in understanding response of medium-sized carnivores to forest fragmentation. Canadian Journal of Zoology 74:2070-2079.

Pedlar, J.H., L. Fahrig, and H.G. Merriam. 1997. Raccoon habitat use at 2 spatial scales. Journal of Wildlife Management 61:102-112.

Prange, S., and S.D. Gehrt. 2004. Changes in mesopredator-community structure in response to urbanization. Canadian Journal of Zoology 82:1804-1817.

Prange, S., S.D. Gehrt, and E.P. Wiggers. 2004. Influences of anthropogenic resources on Raccoon (Procyon lotor) movements and spatial distribution. Journal of Mammalogy $85: 483-490$.

Renfrew, R.B., and C.A. Ribic. 2003. Grassland passerine-nest predators near pasture edges identified on videotape. The Auk 120:371-383.

Robinson, S.K., F.R. Thompson III, T.M. Donovan, D.R. Whitehead, and J. Faaborg. 1995. Regional forest-fragmentation and the nesting success of migratory birds. Science 267:1987-1990.

Rodewald, A.D., and S.D. Gehrt. 2014. Wildlife-population dynamics in urban landscapes. Pp. 117-145, In R.A. McCleery, C.E. Moosman, and M.N. Peterson (Eds.). Urban Wildlife Conservation: Theory and Practice. Springer, New York, NY. 406 pp.

Schmidt, K.A. 2003. Nest predation and population declines in Illinois songbirds: A case for mesopredator effects. Conservation Biology 17:1141-1150. 